\section{Smoking status and planned hospital births}

Re: Outcomes of planned home birth with registered midwife versus planned hospital birth with midwife or physician, Research, Sept. 15. ${ }^{1}$ Would higher rates of smokers among the group of "planned hospital birth with physician" be capable of explaining, at least partially, the unfavourable outcomes for this group?

\section{Enrique F. Barros MD}

Porto Alegre, Brazil

\section{REFERENCE}

1. Janssen PA, Saxell L, Page LA, et al. Outcomes of planned home birth with registered midwife versus planned hospital birth with midwife or physician. CMAJ 2009; 181:377-83.

For the full letter, go to: www.cmaj.ca/cgi/eletters /181/6-7/377\#205222

DOI:10.1503/cmaj.109-2034

\section{The author responds:}

Re letter on smoking status ${ }^{1}$. We tested smoking status as a potential confounder in our analysis and found that it did not change relative risks for perinatal outcomes, perhaps because overall the numbers of smokers in each group was relatively small.

\section{Patricia A. Janssen PhD}

UBC School of Population and Public Health, Vancouver, BC

\section{REFERENCE}

1. Barros EF. Smoking status and planned hospital births. CMAJ 2009 [letter]. DOI:10.1503/cmaj .109-2034.

DOI:10.1503/cmaj.109-2035

\section{Hand hygiene and virus transmission}

We write in response to the recent controversy over the effectiveness of hand hygiene to prevent influenza virus transmission. ${ }^{1}$ Recent studies provide more updated data than the Council of Canadian Academies report from two years ago. A study conducted in Hong Kong found that hand hygiene with or without surgical face masks can prevent influenza virus transmission in households. ${ }^{2}$ N95 respirators are highly effective in theory, but they may not be feasible for use in the household setting. N95 respirators can be uncomfortable to wear for extended periods and have been associated with headaches and other adverse effects in health care workers. Furthermore, a recent study by a Canadian group found that surgical masks were not inferior to N95 respirators in preventing seasonal influenza virus infections in health care workers in hospitals in Toronto. ${ }^{3}$ Current WHO and CDC guidance recommends the use of hand hygiene to reduce transmission in households and community settings. We believe this recommendation is evidence-based and health authorities should support and strengthen this message as pandemic (H1N1) 2009 continues to threaten public health.

\section{Benjamin J. Cowling}

Gabriel M. Leung

Infectious Disease Epidemiology Group, School of Public Health, University of

Hong Kong, Hong Kong, China

Wing-Hong Seto

Hospital Authority, Hong Kong, China

\section{REFERENCES}

1. Brown C, Kondro W. Conflict emerges over value of handwashing as a preventive flu transmission measure. CMAJ 2009. DOI:10.1503/cmaj.109-3066.

2. Cowling BJ, Chan KH, Fang VJ, et al. Facemasks and hand hygiene to prevent influenza transmission in households: a randomized trial. Ann Intern Med 2009;151:437-46.

3. Loeb M, Dafoe N, Mahony J, et al. Surgical mask vs N95 respirator for preventing influenza among health care workers: a randomized trial. JAMA 2009. DOI:10.1001/jama.2009.1466.

For the full letter, go to: www.cmaj.ca/cgi/eletters /cmaj.109-3066v1\#214369

DOI:10.1503/cmaj.109-2031

\section{Correction}

In an article on the CIHR/CMAJ top Canadian achievements in health research, published Oct. $13,{ }^{1}$ Professor Geoffrey Fong's name was misspelled in the paragraph describing his project. The CMAJ apologizes for the error.

\section{REFERENCE}

1. Straus SE. Celebrating 8 projects that improved our world. CMAJ 2009; 181:459-60.

DOI:10.1503/cmaj.109-2036

\section{Correction}

A news story entitled "Opioid prescribing challenges doctors" stated that only British Columbia and Saskatchewan have databases that allow them to track opioid prescribing and identify high prescribers and patients who seek prescriptions from multiple doctors. In fact, Alberta's Triplicate Prescription Program, which was introduced in 1986, also monitors opioid prescriptions.

\section{REFERENCE}

1. Silversides A. Opioid prescribing challenges dotors. CMAJ 2009;181:E143-4.

DOI:10.1503/cmaj.109-2038

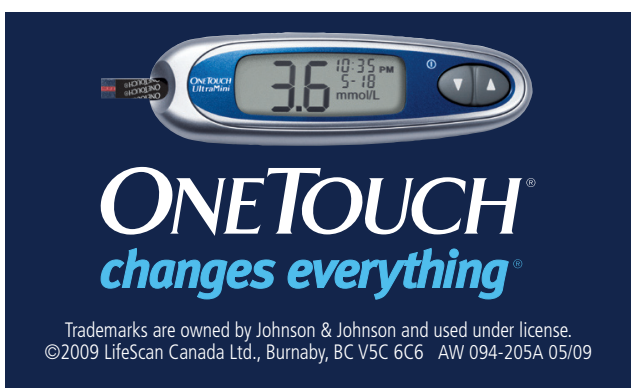

